\title{
REVISTARQUIS/10
}

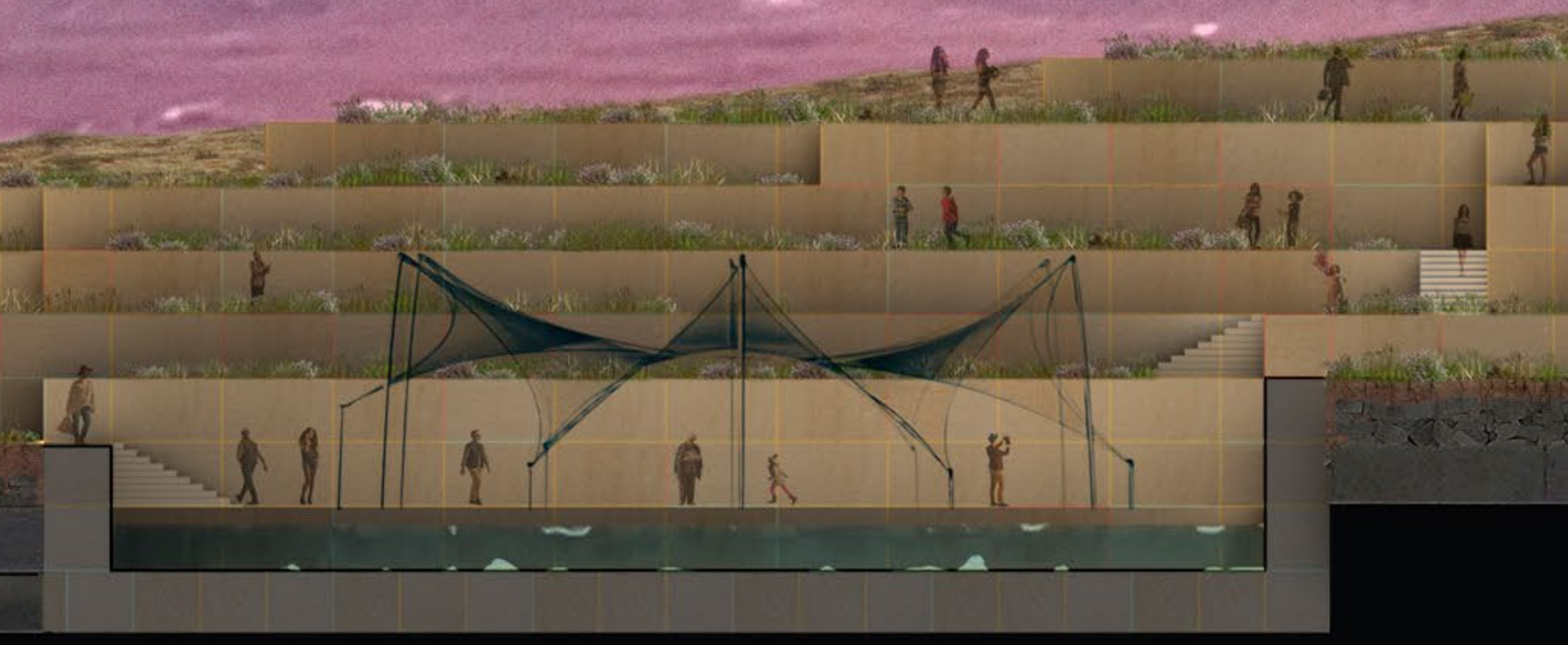


Ciudad y territorio 


\section{Las implicaciones del imaginario dominante "Barrios del Sur" en la producción del espacio urbano}

Lic. Roberto Villalobos Vega, Arquitecto

Invitado nacional

Profesional independiente

rovive723@gmail.com

Recibido: febrero del 2016

Aceptado: noviembre del 2016 


\title{
Resumen
}

La ciudad y lo que se entiende como su realidad, es una dinámica de producción territorial compleja e infinita que se teje recíprocamente entre su dimensión imaginaria (memoria, ideas, sentidos, emociones, etc.), su dimensión empírica (edificaciones, infraestructura, acontecimientos), y la manera en que sus ciudadanos, tanto la sociedad civil como quienes ostentan el poder, amalgaman las distintas variables que la componen para simbolizarla y construirla constantemente (dimensión social). Ante esta premisa, el presente artículo esboza, como problemática urbana, la construcción mediática del territorio, desde el fenómeno de las representaciones de los "Barrios del Sur", un imaginario dominante que se designa bajo generalizaciones negativas del territorio sur del casco central de la ciudad de San José, Costa Rica (Distrito Hospital y Catedral); y su profundo impacto en la producción de la ciudad a nivel de organización territorial (ubicación de miedos y culpas en la urbe), planificación, diseño e inversión urbana, y vivencia socio-espacial del entorno designado.

Palabras clave: barrios del sur; imaginarios urbanos; medios de comunicación; producción del espacio; San José.

\begin{abstract}
The city and what is understood as its reality, is a complex and endless dynamic of territorial production between its imaginary dimension (memory, ideas, senses, emotions, etc.), empirical dimension (buildings, infrastructure, events), and how its citizens, civil society and those in power, amalgamate the different variables that compose it to symbolize and constantly build it (social dimension). Given this premise, this article outlines the media construction of the territory from the phenomenon of social representations "Barrios del Sur" as an urban issue, a dominant imaginary that designates the south part of Casco Central (Central Town: mainly Hospital and Catedral districts), in San José, Costa Rica, under negative assumptions and generalizations; and its profound impact on the city production in terms of territorial organization (location of fears and guilts in the city), urban planning, design, investment, and life.
\end{abstract}

Keywords: barrios del sur; urban imaginary; mass media; production of space; San José. 


\section{Las implicaciones del imaginario dominante "Barrios del Sur" en la producción del espacio urbano}

Roberto Villalobos Vega

\section{Introducción}

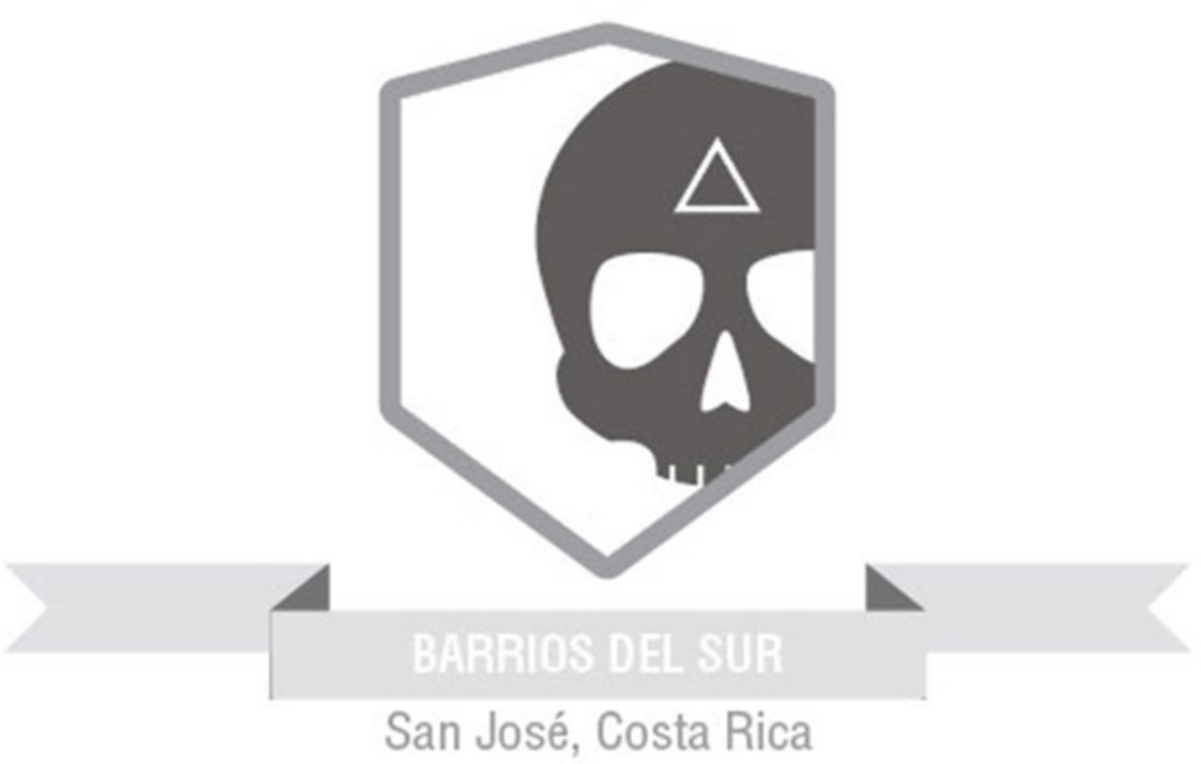

Figura 1. Nociones y discursos sobre el sector sur de San José, densificadas en un emblema de representación territorial negativo.

En la ciudad de San José, Costa Rica, se detecta un fenómeno de representaciones territoriales denominado como "Barrios del Sur", un emblema o constructo imaginario que se difunde mediante narraciones ciudadanas, discursos políticos y su constante referenciaenlosmediosdecomunicación, predominantementeatravésdeproblemáticas totalizadoras que preceden su rostro físico/formal (lugares, personas y actividades), y esquemas valorativos enfocados en alienar lo diferente, lo desconocido y lo que no se adapta al ideal de vida urbana y comportamientos de la media (caos moral y material); ante lo cual, la antropóloga costarricense María del Carmen Araya sugiere: “(...) cuando el ser humano no encuentra respuesta a las cosas cotidianas que no son de su agrado y que le causan dolor, construye mitos e imágenes que las sustituyen." (Araya, M. 2010, p.249). A través de un proceso académico de investigación fenomenológica del espacio 
urbano $^{1}$ en el casco central de San José según el concepto de imaginarios sociales ${ }^{2}$, se constató que este discurso dominante no solo afecta la forma en que se percibe, siente y describe el territorio, sino que se instaura en los modos con que se construye y vive la espacialidad tangible de estos barrios localizados en la parte sur de la ciudad (Distrito Hospital y Catedral). Por ejemplo, en la manera en que se oculta el proceso histórico de su formación, se invalida su aporte patrimonial y cultural en la urbe, se organiza la estructura diferencial del territorio según la ubicación de miedos y culpas (geografía de las representaciones), se define la inversión, planificación y diseño urbano, y se afecta la experiencia entre el ciudadano y su entorno vivencial, entre otras repercusiones. En este sentido, lo imaginado sobre los Barrios del Sur trasciende su inmaterialidad y relativismo para implantarse en el espacio empírico casi como realidad absoluta.

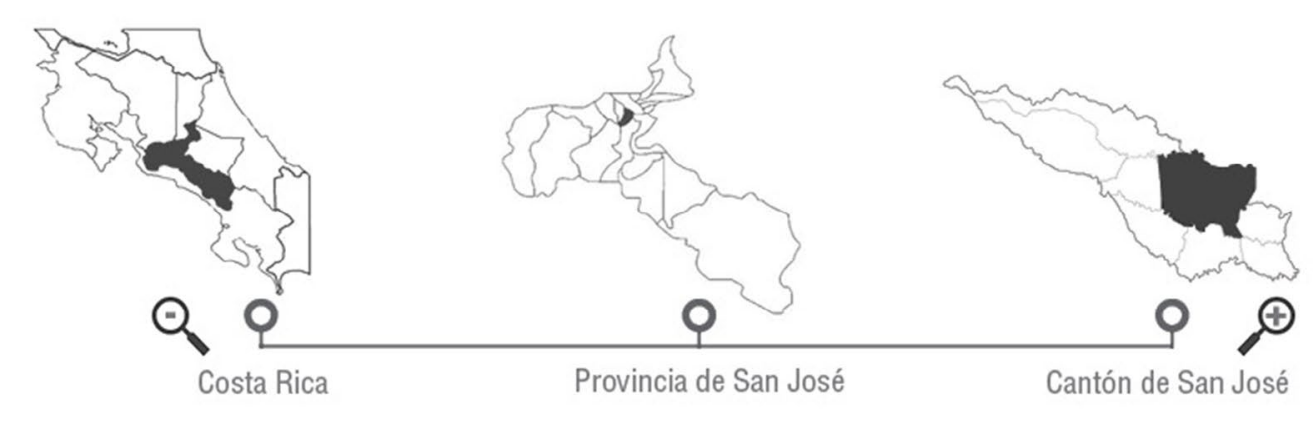

CASCO CENTRAL
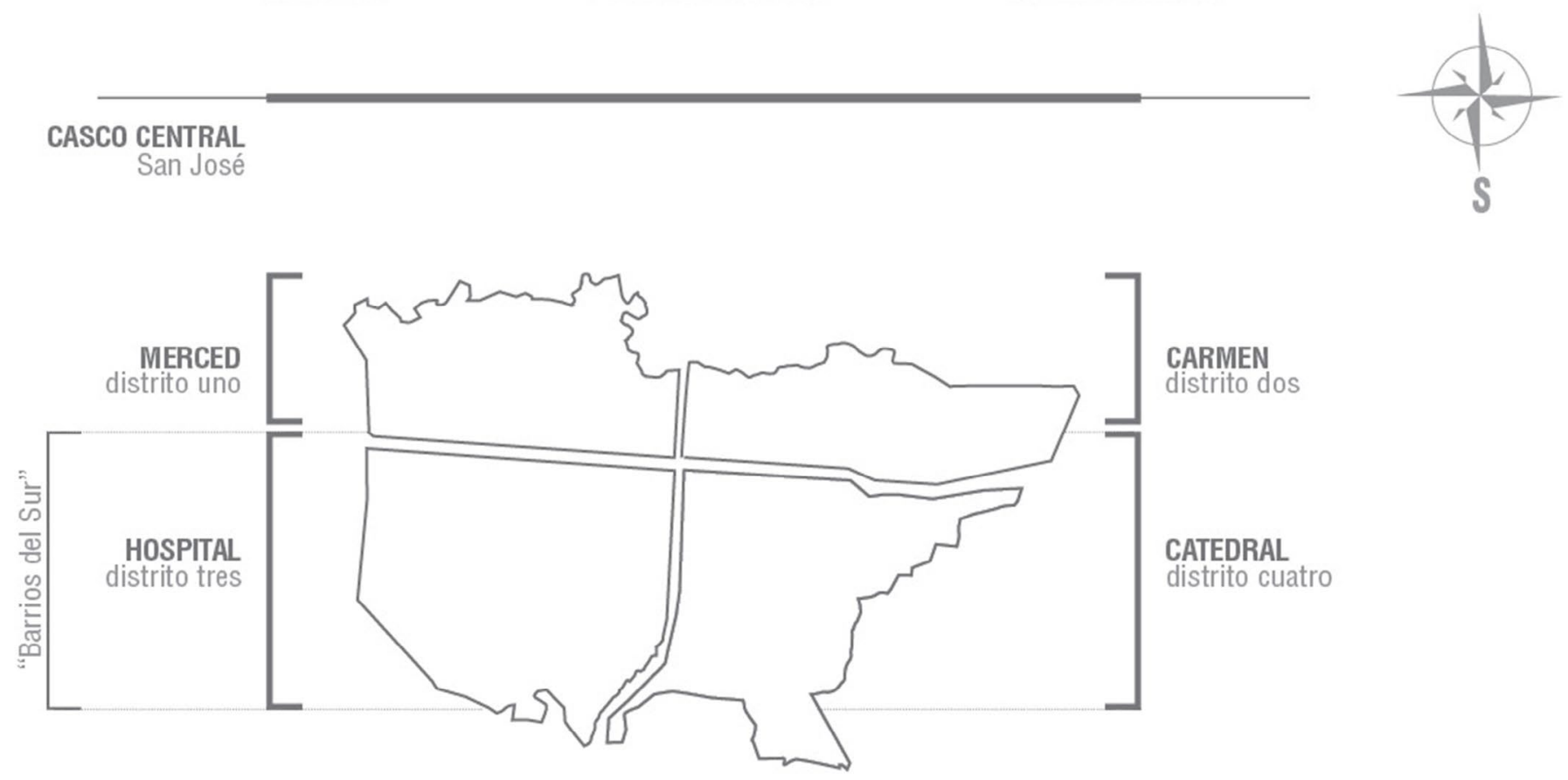

Figura 2. Ubicación general del territorio de estudio "Barrios del Sur” en el Casco Central de San José, Costa Rica.

1 Proyecto Final de Graduación: Barrioscopio del Sur: Vías y Dispositivos de Imaginación desde el Espacio Urbano Caso: Imaginario dominante "Barrios del Sur". Enlace web: https://issuu.com/tillo7231/docs/barrioscopio_del_sur_en_ digital_2.C

2 Concepto abordado en el ámbito internacional por teóricos como el filósofo y psicoanalista turco Cornelius Castoridis, el antropólogo argentino Nestor García-Canclinni, el semiólogo colombiano Armando Silva, entre otros; y en Costa Rica desde las aproximaciones de la antropóloga María del Carmen Araya, y de la Doctora en Estudios Latinoamericanos Florencia Quesada Avendaño, desde un enfoque historicista. 
Considerando lo anterior, se sugiere una relación de influencia recíproca entre la dimensión social, imaginariay empírica del espacio de ciudad para su producción, basada en los argumentos teórico-conceptuales del filósofo y semiólogo colombiano Armando Silva (2006) sobre la composición de la realidad y el acontecimiento urbano según un orden empírico e imaginario superpuestos (Silva, A. 2006, p.118); y los principios de producción del espacio urbano del filósofo francés Henri Lefebvre (1974). Esta hipótesis compuesta plantea que lo imaginado por los habitantes influye en el comportamiento y definición del ámbito físico-formal del territorio, y paralelamente, las distintas manifestaciones tangibles (tanto de forma como de uso) inciden en la configuración del imaginario colectivo utilizado para significar al entorno socio-espacial. Es así como la consolidación de una única manera de percibir al sector "Barrios del Sur" inhibiría la construcción, no solo de otras posibles historias y realidades a percibir, sino también de modos de vivencia y urbanización que contrarresten el discurso hegemónico, constituyendo una crisis en las estructuras productivas de la ciudad que se aglutina y crece.
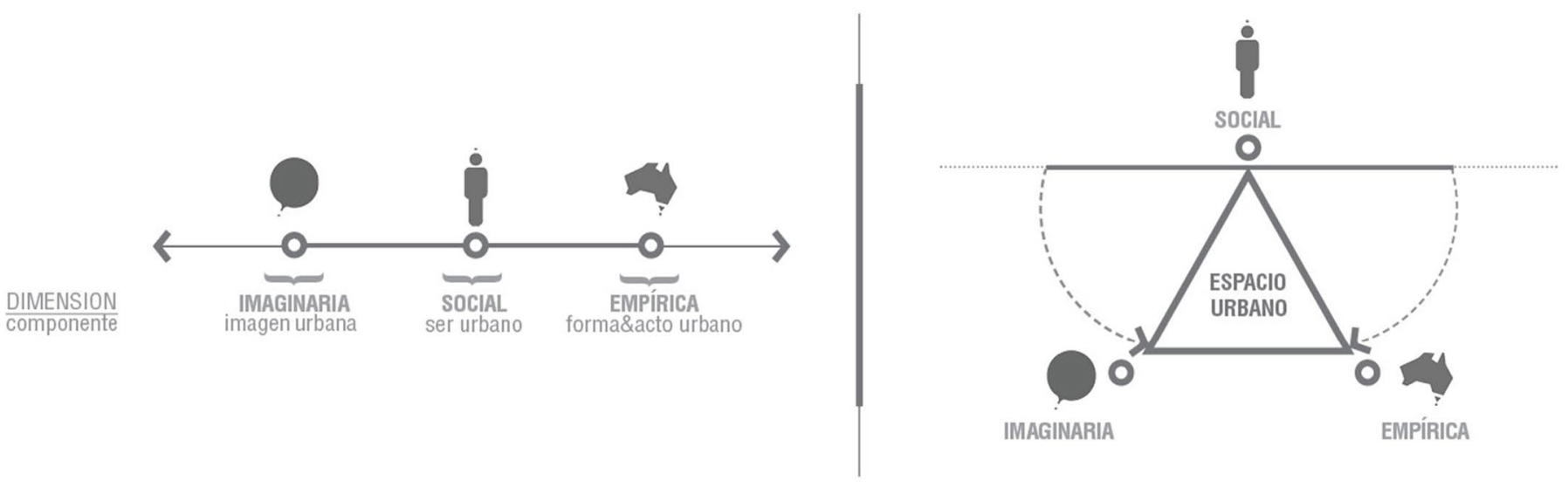

Figura 3. Hipótesis de Investigación. Relación de influencia recíproca entre la dimensión imaginaria, social y empírica para la producción del espacio urbano.

Para construir los argumentos de esta hipótesis, se utilizó como estado de la cuestión las aproximaciones de María del Carmen Araya (2010) a los imaginarios colectivos con que se percibe, difunde y registra negativamente la "realidad" socio-espacial josefina en el siglo XXI; y el acercamiento de la historiadora Florencia Quesada Avendaño (2011) a la formación de la capital costarricense de manera deliberadamente desigual para cada sector demográfico ubicado en la urbe; enfocando ambos referentes teóricos al discurso dominante "Barrios del Sur" y sus implicaciones en el espacio urbano en el que se instaura.

Además, se adoptó el concepto de "imagen" como un "logos-icónico" (la palabra y el icono:: lo dicho y lo mostrado) propuesto por el Seminario sobre la Teoría de la Imagen 
(Elkins, 2010, p.167), para formar una metodología de interpretación cualitativa entre la información narrada sobre el sector sur de San José desde medios de comunicación, (citas, titulares, connotación de la noticia, lenguaje utilizado, etc.), literatura, discursos políticos y la sociedad civil; en contraste con comprobaciones de campo (consulta ciudadana, visitas participativas y no participativas, mapeos, etc.), y datos oficiales disponibles sobre su condición social, económica y administrativa.

A continuación se presenta un esbozo general de la investigación sobre el imaginario dominante "Barrios del Sur" y sus implicaciones en el espacio urbano, enfocándose en la identificación de la problemática a través de la organización, desarrollo urbanístico y vivencia cotidiana para este sector de San José, así como actores, dinámicas y mecanismos hegemónicos con que este discurso se hace operativo en el territorio, principalmente estrategias de urbanización desde la esfera institucional y la producción y reproducción de mensajes de designación territorial según la oferta y demanda en medios de comunicación; entendiendo que las aproximaciones a la dimensión imaginaria de la ciudad, deben hacerse desde la relación con el espacio empírico que los habitantes ocupan como escenario de su manifestación, y viceversa.

\section{Apunte histórico sobre los "Barrios del Sur"}

Inicialmente, es importante revelar que el imaginario "Barrios del Sur" funda sus raíces en el pasado histórico y político-administrativo de San José, a partir de la evolución de la incipiente estructura urbana conocida como "Boca del Monte", a finales del siglo XIX, es entonces donde la ideología de progreso se tecnificó con una serie de estrategias de crecimiento y desarrollo enfocadas en organizar a las poblaciones según el estrato socioeconómico de cada grupo, se establece un sector debidamente urbanizado al Norte de la ciudad, destinado a la clase alta y "pujante", y uno al Sur para la clase proletaria, carente de infraestructura básica (calles, aceras, parques, plazas) y apoyo residencial. Esta maniobra debe de ser entendida no solo como un proceso de formación geográfica, sino como el inicio de una lucha de dominio por y desde el espacio urbano de manera intencionada y desigual.

Tal como refuerza Florencia Quesada en su libro "La modernización entre cafetales: San José, Costa Rica, 1880-1930" (2011) "La renovación urbana fue la expresión material de reorganización de un espacio social de poder. La deliberada segregación del espacio urbano que se inicia en este período [a partir de la promulgación de la Ley de Ensanches, en 1887], tuvo como consecuencia la creación en sus extremos de dos ciudades, una, la San José burguesa (...) a lo largo de la Avenida Central, los parques, 
Morazán, Nacional y La Sabana. La otra, la que creció sobre todo al sur y al noreste, la San José popular que comenzaba a conformarse y a quedar geográficamente segregada y rezagada de ese tren del progreso, de cuyos vagones fue deliberadamente sacada. La ciudad marginal..." (Quesada, 2011 p. 45).

En una sociedad en donde el estatus socioeconómico es relacionado directamente con los esquemas valorativos de cada grupo social (clase alta: "lo lindo" y "lo bueno"; clase baja: "lo feo" y "lo malo"), los efectos de las desigualdades y frustraciones socioespaciales, como el aumento en la criminalidad, violencia, enfermedades, incremento de la pobreza, etc., comienzan a ser cada vez más atribuidos a los territorios del Sur y otros sectores populares, se propicia el reemplazo de la experimentación física como forma de producir el sentido y espacio urbano por la predominancia del acto denominativo (rumores, mentiras, chismes, suposiciones). En esta instancia, se podría decir con la premisa anunciada al inicio del texto, que una condición mayoritariamente empírica, como lo es la localización poblacional, mutó hasta convertirse también en un referente imaginario en el sentido común de los josefinos.

\section{Construcción de los imaginarios urbanos a través de los medios de comunicación}

De esta manera se introduce un componente fundamental en la ecuación que da como resultado las distintas percepciones, narraciones y formas de trato asociadas al sector Sur de San José. La producción, difusión, recepción y reproducción de mensajes territoriales como mecanismo dominante para interpretar y transformar al espacio urbano (sentido, forma y uso), especialmente a través del acceso cada vez menos restringido y filtrado a las tecnologías de la información y comunicación.

Una de las vías principales que potencian la construcción mediática del territorio es a través de las estructuras de comunicación masiva, en donde se transforman los acontecimientos y realidades socio-espaciales en mensajes como productos de consumo según la demanda de la población urbana (morbo, miedo, entretenimiento). Por ejemplo, el caos en la capital como discurso imperante de la situación actual del casco central de San José.

Desde su posición privilegiada (acceso doméstico, laboral, de ocio, etc.), los medios de comunicación pueden interpelar a casi la totalidad de la comunidad urbana sobre la realidad del espacio de ciudad construida virtualmente (San José mediatizado), por lo que se vuelven la voz dominante de la urbe, sobre todo a través de un uso excesivo 
de la "nota roja" o el suceso, eje medular de la oferta informativa nacional, y principal sección en que se menciona a los "Barrios del Sur"; convirtiéndose en una fuente desde donde se alarma, influye, instruye o se persuade al pensamiento colectivo sobre alguna realidad $u$ objetivo del territorio representado, a la vez que se impacta en el comportamiento perceptual, cognitivo, emocional e ideológico de la población que recibe los mensajes.

Lo anterior se puede respaldar a partir de los resultados connotativos de una búsqueda web sobre titulares que mencionan territorios pertenecientes al denominativo "Barrios del Sur" en San José; en donde hay predominancia negativa en el lenguaje y contenido: "Joven muere tras balacera dentro de auto en barrio Cuba" (Miranda, 2013); "Cinco personas irán a prisión por secuestro extorsivo contra hija de empresario en Barrio Cuba" (Delgado, 2012); "Cuartuchos anidan miseria y delincuencia" en Cristo Rey, y alrededores (Arguedas, 2004); "Escolares agredieron a dos educadores." (Vargas, 2004); "20 cuadras que nunca querrá conocer" (Araya, 2010).

De esta manera, percibir a los territorios mayoritariamente desde la selección periodística o mediática en general, fomenta una dislocación en la cultura y sentidos de un lugar; fenómeno que puede ser entendido como un tipo de "desterritorialización" del espacio urbano (contrario a la territorialización o formación del entorno físico e imaginario in situ), privando a un sector de la ciudad a auto-gestionar su propia identidad, para imponérsele otra desde las estructuras hegemónicas de difusión y sus mecanismos operativos.

En esta práctica, el imaginario y las suposiciones territoriales se originan y fortalecen desdela exposición de situaciones posibles pero explotadas hasta ellímite del melodrama informativo. Así, la presentación de un acto delictivo u otro acontecimiento en barrio Cristo Rey (Distrito Hospital), deja por fuera del marco mediático todo aquello que no fundamente lo que se desea mostrar y decir de manera inmediata y alarmante. Esto es lo que da credibilidad a las nociones del territorio difundidas, pues el observador se puede sentir identificado con la monopolización de esta única realidad o única historia presentada para este barrio, sin importar la metodología escueta con que se presentan los datos.

Además, como parte de la difusión de generalizaciones territoriales desde medios masivos de comunicación, la sociedad civil asume su rol activo como receptora y reproductora de los mensajes divulgados. Los ciudadanos, tanto quienes habitan los Barrios del Sur, como quienes no, interpretan, subjetivan y se apropian de los discursos recibidos según su propio acervo simbólico (cultural e individual), para hacerlos parte 
de sus estructuras y prácticas sociales, ya sea como material para la construcción de la propia identidad (reconocerse y reconocer al "otro" en el caos); como promotor de actitudes de alarma, desasosiego y prevención; o como fundamento para emitir el mensaje desde sus propios medios, acto que consolida el proceso y legitima el mensaje.

Un ejemplo de lo anterior se evidencia en el extracto de la canción "Los Barrios del Sur", , de la agrupación Latin Crew, autoproclamada como la pandilla del "guetto, quienes encuentran en las representaciones despectivas de violencia y agresión, un emblema de su propia identidad y de su territorio: "Representando a "San Sebas", "La Cartonera”, Cristo Rey, Las gradas, Barrio Cuba, Sagrada, "bajo la puñalada", Hatillo 5 , (...) es la dura realidad de los barrios del sur, donde reina la maldad y aniquilan al "full", (...) escribo lo que siempre veo yo en los barrios, todos los días hay gentes con mentes de sicarios, donde muere gente a diario, nadie sabe cuándo porque no existe el horario (...) La policía vale "cuecha", no entran, se aterran, saben que se la juegan, la bomba está que estalla, mejor no vea nada y se calla, donde vivo la gente por sueldo mata, sabes que soy del sur, odiando al full" (Latin Sur Crew, (2011) Los Barrios del Sur).

Los territorios precedidos por la noción de desesperanza, el amarillismo mediático, y la falta de sentido crítico por parte de sus observadores y hasta ocupantes, sucumben ante el dominio de la imagen antagonista confabulada para estos, inhibiendo aún más la oportunidad de andar, percibir e imaginar nueva información a través de prácticas territoriales como la experiencia, y catalizando la producción de miedos, inseguridades y acusaciones densificadas en ellos; por lo que, de acuerdo a la premisa de estudio, se podría indicar que la consolidación de un constructo imaginario sobre un territorio, altera las formas y comportamientos empíricos manifestados en él.

\section{Implicaciones del imaginario "Barrios del Sur” en la polarización territorial}

El discurso dominante, "Barrios del Sur" no solo provoca el alejamiento y la desigualdad en el aspecto intangible de San José (imaginario, emocional, social, etc.), sino que también facilita la creación y fortalecimiento de marcas territoriales (zonas y límites) que fragmentan antagónicamente la vida en la ciudad y su pobladores más allá de meras divisiones políticas y/o morfológicas. Un efecto asociado a la polarización del espacio urbano diferencial (el entorno oficial subjetivado y transformado por sus habitantes) y 
a los mecanismos técnicos de ordenamiento y desarrollo urbano (planes reguladores, proyectos de inversión, connotaciones de intervención pública, etc.).

Inicialmente, la segregación socio-espacial del territorio según el imaginario colectivo en San José, se organiza en un esquema tríadico Norte/Centro/Sur del entramado urbano compuesto por los cuatro distritos del Casco Central: Merced, El Carmen, Hospital y Catedral; muy afín a la distribución inicial con que se urbanizó la ciudad desde el siglo XIX. Los dos primeros distritos constituirían el sector Norte de esta organización polar (Merced y El Carmen); mientras que los otros dos al sector o polo Sur (Hospital y Catedral). Ambas agrupaciones territoriales se subdividen en su borde político-administrativo de convergencia para aportar una porción del territorio a lo que el imaginario reconoce como el "Centro" de la capital; representado principalmente por la emblemática Avenida Central (Paseo Colón - Av. 0).

El "Polo Norte" se destaca en el imaginario colectivo como el territorio idealizado, cuyas características se narran con más estima y sentido de pertenencia por la población en general, por lo que se vuelve el sector de referencia y comparación con "los otros" territorios del casco central, sobre todo en la dialéctica Norte/Sur. Su locación emocional se acerca más al "centro" o núcleo de la cultura y vida urbana de la capital (histórico-patrimonial, económica y social), principalmente el distrito de El Carmen, con su estética de clase alta (viviendas convertidas actualmente en comercios turísticos, artísticos y gastronómicos) y apellidos de alcurnia utilizados para nombrar con prestigio internacional a los barrios que se fundaron en este sector (barrio Amón, barrio Tournón, barrio Otoya y barrio Aranjuez) $)^{4}$.

Los distritos correspondientes al "Polo Sur" de la ciudad, representan al territorio estigmatizado, especialmente el distrito Hospital, referenciado como una de las "zonas rojas" indiscutibles de San José según narraciones ciudadanas y medios de prensa5. Su presencia en la ciudad se limita al discurso mediático de alarma, y a referencias de su culpabilidad en los conflictos socio-espaciales de San José, tal como lo expresa María del Carmen Araya en su libro "San José: de Paris en miniatura al malestar de la ciudad": "Estos son vistos, implícitamente, como seres poseídos por fuerzas diabólicas que se

\footnotetext{
4 Aunque no es el enfoque de la investigación sobre "Barrios del Sur", es importante acotar divisiones a lo interno del mismo "Polo Norte" del Casco Central, en donde se identifican sectores cuya imagen ante la opinión pública se encuentra igualmente socavada con atribuciones de inseguridad, contaminación y deterioro, sobre todo en el Distrito Merced (Barrio México, Paso de la Vaca, Mercado Borbón, etc), lo cual crea una relación valorativa con los barrios más al sur de la capital, a través del título "zona roja” en San José. Los barrios más relacionados al ideal de vida josefina, constituirían los ubicados mayoritariamente en el Distrito del Carmen (Otoya, Amón, etc.).

5 Descripción de las cercanías del barrio Cristo Rey como la "zona roja” en noticia "Escasean granos en bodegas de grupo que alimenta a niños e indigentes" (Vargas, 2013).
} 
extienden desde los barrios del sur de San José, pasan por los alrededores del Parque Morazán y llegan a los "otrora dijes capitalinos”, es decir, los barrios de Amón y Otoya [Distrito de El Carmen]" (Araya, 2010, p.221).

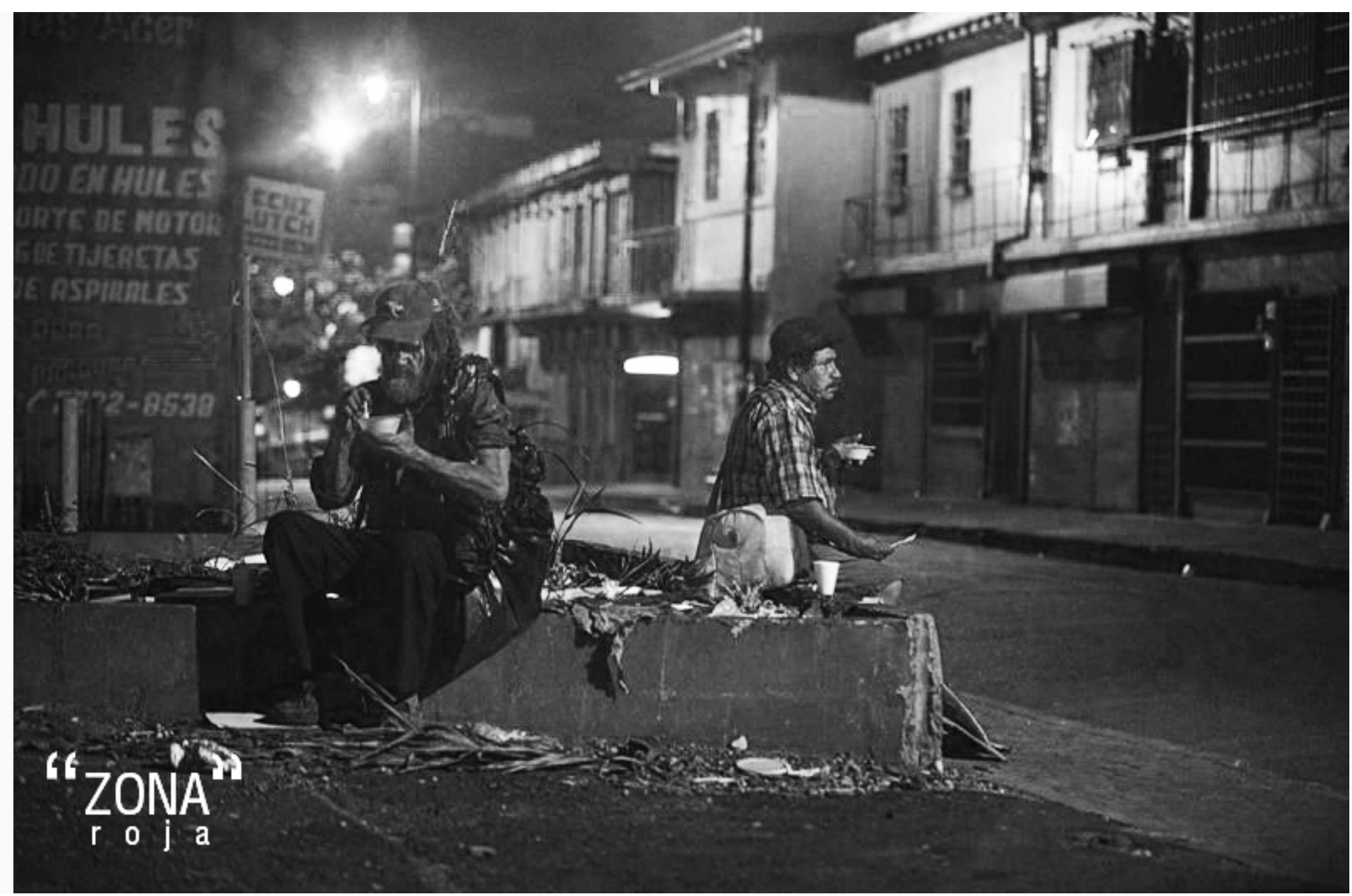

Figura 4. En 2013 se describe un acontecimiento en las cercanías del barrio Cristo Rey, en el Distrito Hospital, de la siguiente forma "El 9 de julio, dos indigentes de la zona roja recibieron comida de la Asociación Obras del Espíritu Santo" (Vargas, O. La Nación 2013), fotografía por Pablo Montiel.

Cada región cardinal representa una carga simbólica con su respectiva connotación valorativa y características tangibles e intangibles. Entre más cercano a estas esté un territorio, más relacionado estará a sus características formales y de representación. Por ejemplo, zonas pertenecientes al distrito Hospital que se encuentren más cercanos al "Centro" (parte norte del distrito), no necesariamente son destino de estigmatizaciones o se vinculen con problemáticas socio-espaciales, pues adquieren otra carga polar (la del norte de la ciudad); tal como el caso de barrio San Bosco, el cual es territorio idealizado entre los habitantes estigmatizados del sur ${ }^{6}$.

Igualmente, cuanto más al sur se encuentre una comunidad, las imágenes negativas se condensan en áreas más amplias y con mayor arraigo. Así por ejemplo, en sectores como Barrio Cuba, Cristo Rey, Carit, Pacífico y Los Ángeles, en donde las problemáticas socio-espaciales se perciben y difunden con más fuerza a través de los distintos medios 
hegemónicos y ciudadanos de difusión7; e inclusive en territorios más meridionales, en donde se reconoce el surgimiento de un nuevo "Sur" simbólico fuera del casco central, principalmente emplazado en sectores como los Hatillos, Alajuelita, Paso Ancho, Desamparados, Aserrí, San Sebastián, y Sagrada Familia, evidenciando que las nociones dominantes de lugar agrupan territorios kilométricamente distantes por un lado, y separan sectores físicamente colindantes por otro.

\section{La realidad socio-espacial de "Barrios del Sur" en relación al imaginario dominante}

Desde una perspectiva oficial se denota el rastro de la polarización territorial, fortalecida por las representaciones generalizadas a través de evidencia cuantificable sobre el estado socio-económico y espacial de la ciudad. Por ejemplo, la brecha existente entre el distrito idealizado de El Carmen (Polo Norte) y el estigmatizado distrito Hospital (Polo Sur), según el índice de desarrollo social (Departamento de Observatorio Municipal, MSJ. 2011, s.p), en donde el primero destaca con mejores calificaciones en el ámbito educativo, económico, salud y participación social (85.5 contra 68.6). Este dato podría representar numéricamente el estancamiento social y económico vivido por los sectores del Sur en San José, a la vez asociado a las percepciones y narraciones negativas.

Así mismo, la discrepancia entre el valor del suelo ${ }^{8}$ en ambas zonificaciones (Norte y Sur), argumenta los efectos de las desigualdades simbólicas y empíricas vividas según el sector de residencia en la ciudad, en este caso a nivel de rentabilidad y valoración económica del territorio. Se constata una diferencia promedio de 215000 colones entre el precio del metro cuadrado de barrios del distrito Merced, en el norte (barrio Amón: $250000 \mathrm{col} / \mathrm{m} 2$; barrio Otoya: $290000 \mathrm{col} / \mathrm{m} 2$ ), en comparación a zonas devaluadas en el distrito Hospital (Barrio Cuba: $50000 \mathrm{col} / \mathrm{m} 2$; barrio Cristo Rey: $60000 \mathrm{col} / \mathrm{m} 2$ ).

Otro dato que destaca es el referente a la proporción de área verde y de recreación en cada distrito. Al comparar un área promedio de $31.46 \mathrm{~m} 2$ por habitante del distrito Merced (Norte) vs $5.87 \mathrm{~m} 2$ por habitante del distrito Hospital (Sur), se verifica no solo una diferencia significativa en cuanto al acceso a lugares potenciales de esparcimiento

\footnotetext{
7 Su relación al denominativo "Barrios del Sur" se hizo mediante una búsqueda en medios de prensa bajo el formato web, utilizando la palabra filtro: "Barros del Sur"; por lo que se establecieron como los territorios que cargan con más fuerza y de manera comprobable, las representaciones negativas difundidas como imaginario urbano del Distrito Hospital de San José.

8 Indicador del panorama de inversión y cotización de los espacios según sus recursos, servicios básicos y valor agregado (condición económica del barrio, percepción de seguridad, estado de la infraestructura pública, etc.).
} 
y convivencia, pilares fundamentales de la activación socio-espacial en la ciudad a través de la interacción de ciudadanos entre sí y con su entorno de ocupación (sentido de pertenecía, uso, etc.), sino que evidencia también un déficit en el sector Sur de acuerdo a recomendaciones de la Organización Mundial de la Salud (OMS) de $10 \mathrm{~m} 2 \mathrm{a}$ $15 \mathrm{~m} 2$ por habitante (Conpes, 2012, p.7)9.

\section{Incidencia del imaginario dominante en la vida urbana de los "Barrios del Sur"}

Los mecanismos espaciales con que se representan y segregan los territorios no se limitan a escalas generales o distritales, sino que también provocan el distanciamiento en relaciones inter-barriales e intra-barriales. Así, habitantes pertenecientes a los barrios estigmatizados reproducen patrones de designación destructiva para referirse entre sí, casi como una réplica del juego de expiación de culpas en el que está inmerso la sociedad urbana en general; como lo refleja el costarricense Eduardo Oconitrillo en el capítulo "El barrio Carit" del libro "Historias de mi Barrio: el San José de ayer" (1997, p.235): "Los habitantes lo consideran aún un vecindario tranquilo, y dicen que "aquí no es Cristo Rey" ${ }^{10}$; o consultas ciudadanas a los habitantes de barrios pertenecientes al título peyorativo "Sur": "Por donde yo vivo es tranquilo... Por la calle de abajo [sur] vive mucho "maleante" se oye y pasa de todo" ${ }^{11}$

De esta manera se introduce otra incidencia del imaginario dominante "Barrios del Sur" en el espacio urbano, en este caso asociada a la íntima relación del habitante con su entorno de ocupación, en donde percepciones, "otredades" antagónicas y representaciones negativas del territorio, se instauran en la experiencia y formas físicas del hábitat empírico para transformarlo.

Cuando rumores y percepciones de peligro o inseguridad comienzan a generalizarse como el estado dominante de un barrio (calles, parques, zonas residenciales, etc.), la imagen colectiva hacia su propio entorno se convierte en la de un territorio del miedo, a la vez que sus pobladores se transforman en habitantes desconfiados, temerosos y con poco sentido de pertenencia y apropiación por símbolos socio-espaciales que generan rechazo y culpa ante la población urbana general. Las actitudes y prácticas en

\footnotetext{
9 Se debe resaltar que el déficit se enfoca en un concepto de espacio urbano simplificado a área verde, por lo que es posible imaginar posibilidades en infraestructuras alternativas del territorio en caso de intervenciones para aumentar este valor no en cantidad sino en calidad, por ejemplo en la calle, las aceras, lotes residuales, reciclaje de edificios, etc.

10 Representación que resume la postura de un barrio que históricamente se ha tratado de desligar de sus vecinos más próximos, como Cristo Rey y Barrio Cuba.

11 Consulta a mujer de 37 años en Barrio Cuba al pedirle una descripción de su barrio.
} 
el territorio designado se modifican, generalmente en términos de disminución en la frecuencia, temporalidad y cantidad de actividades realizadas en estos espacios, lo cual afecta sus usos, su estado físico, las relaciones sociales propiciadas ahí, y la manera en que se desarrolla la identidad colectiva del lugar a partir de su experimentación.

Los territorios temidos y arrebatados de la recurrencia y convivencia comunal se convierten enlugares desérticosyvulnerables a las amenazas, inicialmenteimaginarias, al ser ocupados por personajes y actividades ajenas y perjudiciales para la vida barrial (drogas, indigencia, violencia, etc.), sin que haya ningún tipo de vigilancia natural o práctica vecinal que las inhiba. Es así como la producción del sentido y espacio urbano deja de ser una práctica sustraída desde la propia experiencia, y se somete únicamente a las referencias externas de difusión, evitando la posibilidad de nueva información otorgada por el entorno, o de acciones empíricas para modificar su realidad.

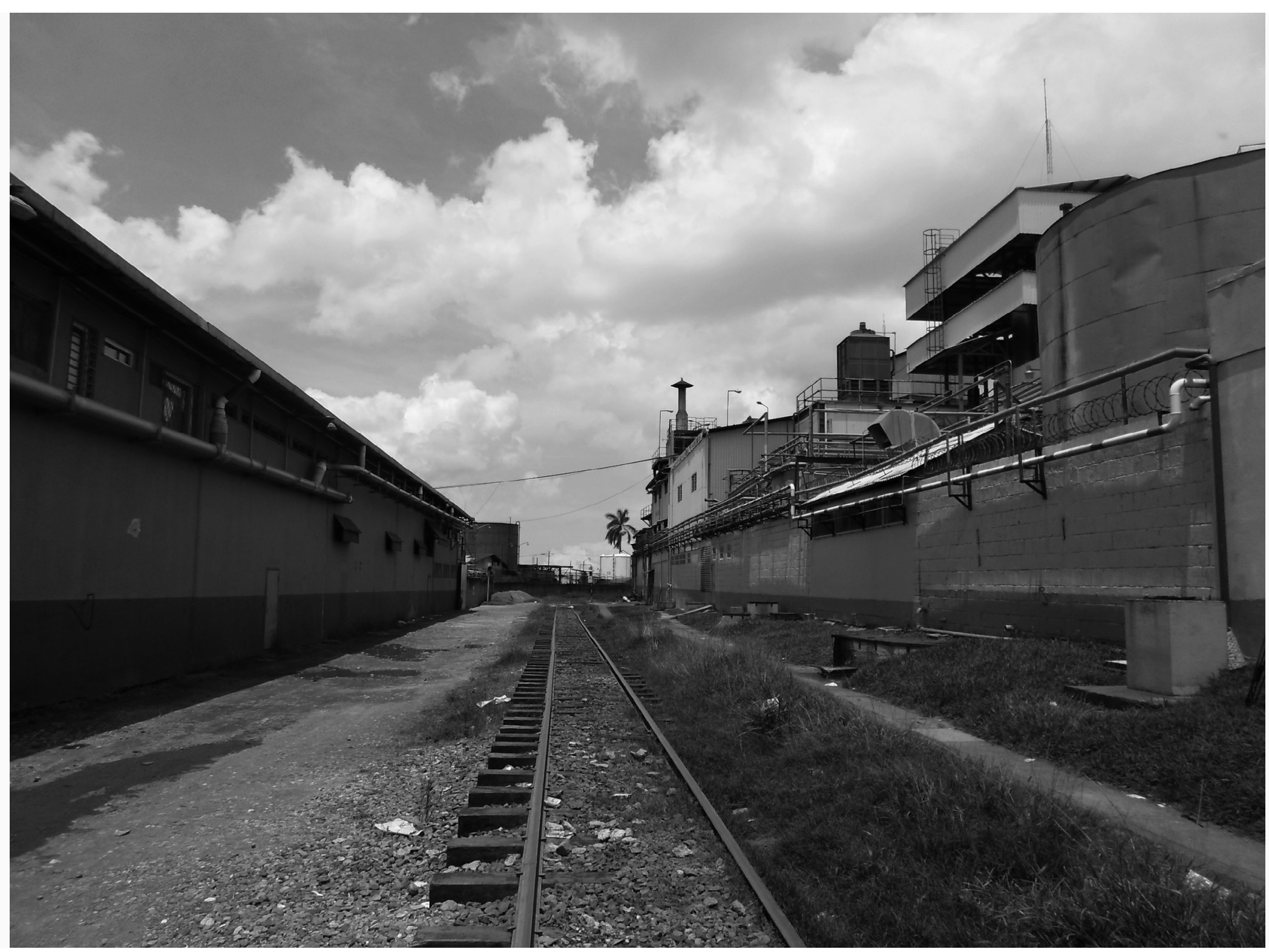

Figura 5. Las percepciones negativas en conjunto con tipologías urbanas inhibidoras de la convivencia vecinal (fábricas, bodegas, tapias, etc.), vulnerabilizan la vivencia del espacio barrial y fomentan la consolidación de entornos solitarios y potencialmente peligrosos para los habitantes. Imagen propia tomada en los alrededores de la NUMAR en Barrio Cuba, Distrito Hospital 2013 


\section{Implicaciones del imaginario dominante en el desarrollo urbano del casco central}

A mayor escala, las designaciones destructivas también se convierten en construcciones ideológicas fácilmente instrumentalizables que sirven para imponer determinados intereses, acciones y omisiones por parte de quienes ostentan el poder de decisión y ejecución en la ciudad en los sectores simbólicamente dominados y vulnerabilizados ${ }^{12}$, aprovechándose del desasosiego y alarma de la comunidad urbana en general para su apoyo.

Un ejemplo de lo anterior es la profunda influencia del imaginario dominante "Barrios del Sur" en el "Plan de Regeneración y Repoblamiento de San José"”, actual estrategia que organiza las principales pautas y metodologías de desarrollo urbano en el casco central de la ciudad de San José.

El "Plan de Regeneración y Repoblamiento de San José" atiende a nociones generalizadas de deterioro en la infraestructura pública y a la supuesta ausencia de habitantes en la ciudad debido al éxodo demográfico desde la década de los ochentas hacia nuevos puntos cardinales del área metropolitana (principalmente Este y Oeste), implícitamente atribuido al esparcimiento del caos proveniente de territorios populares y estigmatizados del casco central como el sector Sur de San José.

La estrategia trabaja en dos ejes principales; por un lado, la regeneración se centra en invertir y renovar la estructura socio-espacial de una ciudad cuya imagen urbana se generaliza como deficiente y con problemáticas de "indigencia, pobreza, degradación, inseguridad, ventas ambulantes, contaminación, saturación vial, (...)" (Municipalidad de San José, 2008, p.5). Por otro lado, el repoblamiento está enfocado en el desarrollo residencial compacto y mixto ${ }^{14}$ para la atención demográfica y la búsqueda de una ciudad comparable con las grandes metrópolis mundiales.

Ambos ejes se plantean de manera excluyente para los sectores populares de San José, especialmente en el "Polo Sur", pues están definidos para un público meta que no necesariamente corresponde a quienes habitan, en su mayoría, el casco central

\footnotetext{
12 A través de herramientas como el objeto arquitectónico, estrategias de ordenamiento territorial, proyectos y directrices de inversión.

13 Formulado, gestionado y ejecutado en una asociación entre el sector privado (propietarios de tierras, inversionistas, desarrolladores inmobiliarios y clientes finales), la academia y la esfera institucional, principalmente la Municipalidad de San José, según el Decreto Ejecutivo No 31730-MIDEPLAN-MIVAH, Procuraduría General de la República 2004 (MSJ, 2008 , p.8).

14 Esquema de construcción vertical que mezcla funciones habitacionales, con comercios y servicios afines.
} 
actualmente. En su lugar, el perfil de habitante para San José se idealiza en personas jóvenes profesionales, de clase media y media-alta, "funcionarios públicos y de empresas privadas vinculados a los servicios financieros, el comercio y principalmente el turismo" (Municipalidad de San José, 2008, p.3); dejando por fuera de los proyectos de mayor inversión e impacto socio-espacial, a aquellas poblaciones con las que se justificó y urgió el proyecto en un inicio, tal como lo expresa el documento oficial de la estrategia: "De ninguna manera, la Municipalidad de San José, ha pensado en atender las necesidades habitacionales de los sectores con menos recursos, ya que para esto, el Estado central cuenta con el sistema nacional para la vivienda" (Municipalidad de San José, 2008, p.5).

Para una muestra de la población posiblemente excluida de estos proyectos urbanos, se presenta una interpretación de datos desde la unión del índice de pobreza en los distritos Hospital y Catedral ("Polo Sur") (MSJ, censo 2000), en donde se evidencia que en el sector más extenso de los cuatro distritos, es donde se concentra la mayor cantidad de personas en estado de pobreza, con 776 personas en el distrito Catedral ( $6 \%$ de su población total) y 3,141 personas en el distrito Hospital (16.3\% de su población total), en este último, traducido en 929.3 habitantes/ $\mathrm{km} 2$ en condición de pobreza, y sin aspiraciones a ser tomados en cuenta oficialmente en inversiones de infraestructura urbana pública y/o residencial.

Además, al comparar el valor de mercado del metro cuadrado de construcción de 625,000 colones/m2 en $160 \mathrm{~m} 2$, de uno de los proyectos residenciales desarrollados en el distrito Hospital dentro del Plan de Repoblamiento ${ }^{15}$ (valor total del apartamento: 100,000.000 colones), con el ingreso promedio por habitante del distrito Hospital de 58.960 colones mensuales $^{16}$, se constata una diferencia importante entre la capacidad de pago de los habitantes del sector sur, y las ofertas domiciliarias disponibles en su territorio según el plan, que por sí mismas, presentan precios altos incluso para la clase media, con lo que se refuerza la exclusión implícita de este discurso oficial de repoblamiento.

Según declaraciones del Jefe del Departamento de Gestión Urbana de la Municipalidad de San José, Vladimir Klotchkov, no existe un estudio objetivo de un antes y un después de la implementación del Plan de Repoblamiento en el casco central (Klotchkov, V. en Mora, E. 2013), lo cual representa una desventaja en la evaluación de su impacto

15 Condominios Residenciales “6-30" en Barrio San Bosco, Distrito Hospital. Noviembre 2013, desde: http:// www.inmobiliaria24.com/costa-rica-es/category-173/venta-condominio-vertical-residencial-6-30san-jose-costarica/335046

16 Marzo 2013 desde: https://www.msj.go.cr/informacion_ciudadana/SitePages/hospital.aspx 
para los sectores populares, sin embargo, se registran dos propuestas que permiten articular brevemente el discurso subyacente e impacto para los "Barrios del Sur" de San José, desde las estructuras hegemónicas de producción de la ciudad.

La primera trata del "Centro de Servicios Comercial y Cultural del Sur" (Municipalidad de San José, 2005), un incipiente proyecto planteado desde 1991, en el lote de la Estación al Pacifico, en el distrito Hospital, punto estratégico para las intenciones hegemónicas de recolonizar el Sur de la capital (material y moralmente). Éste se propone como apoyo a la regeneración vial, en este caso, del Tren Urbano Metropolitano y otros medios de transporte, acompañado de terminales de buses, taxis, centros de comercio, oficinas, museos y propuestas habitacionales para clase media; sin embargo, no contempla ningún beneficio u objetivo concreto para los territorios y habitantes inmediatos a este terreno a pesar de su realidad socio-económica desventajosa, y además, opera bajo una búsqueda de estructuras y comportamientos asociados al consumo como ideal de esparcimiento, progreso social y solución de conflictos en la ciudad; un patrón que desensibiliza el sentido de cultura y convivencia urbana desde la interacción social.

Vladimir Klotchkov expresa: "La Municipalidad tiene entre sus prioridades reforzar el rol capitalino de San José y repoblar su zona central con las actividades políticas, económicas y culturales cuya imagen deseada podemos describir como un extenso centro comercial y de servicios - ¿el mall más grande de país?- a cielo abierto, con plazas, galerías y bulevares y, a la vez, poblado con nuevos residentes" (Mora, 2013, p.10).

Otro plan localizado es "San José Posible", una colaboración entre la Municipalidad y el Instituto de Arquitectura Tropical (miembro de la Comisión de Regeneración y Repoblamiento), que consiste en el ordenamiento del transporte privado y público, y la recuperación del espacio urbano en cincuenta y tres "manzanas" en el distrito Hospital y Catedral, entre Avenida 4 y Avenida 10, Calle 11, y Calle 16 (Ugarte, 2013): "Porque es una de las zonas más decadentes y necesita una regeneración inmediata antes que sea muy tarde" (...) "Porque le llegó el momento a los ciudadanos de exigir su derecho a tener una ciudad decente y no el basurero en ruinas plagado de indigentes y drogadictos existente en la actualidad" (Instituto de Arquitectura Tropical, s.f. ${ }^{17}$ ).

Aunque "San José Posible" es una propuesta con potenciales efectos positivos para la dinámica general del casco central de San José, en tanto reconoce la importancia 
del espacio público, los problemas viales como un problema cultural, y la necesidad por disfrutar la ciudad, entre otras; su lógica de análisis y de acción se fundamenta en una serie de supuestos asociados al discurso dominante del área Sur de San José (lo negativo), descalificando totalmente las características y modos de vida de los actuales pobladores del área de intervención, mientras se lidia metafóricamente con manzanas "podridas" para salvaguardar las idealizaciones de una ciudad atractiva para clases medias. Como prueba de esto, en publicaciones relativas a los alcances del proyecto, la integrante del Instituto de Arquitectura Tropical Jimena Ugarte declara: "En esta zona, es factible y posible arrasar con manzanas completas porque no perdemos nada, dado que son ruinas vergonzosas, en las cuales queríamos promover e insertar la iniciativa privada y conjuntos habitacionales para clase media" (Ugarte, 2013, p.6).

Como síntesis general del análisis cualitativo de "Barrios del Sur" como imaginario dominante y sus efectos en el entorno físico y empírico de la ciudad (datos oficiales, cartografíadiferencial, relatos, discurso político, efectoscognitivosyde comportamiento en el hábitat barrial), se puede sugerir que las aproximaciones urbanas hacia este territorio, principalmente desde el híbrido entre el ámbito institucional y de inversión privada, se hace desde una metodología paradójica en términos de sobre-exposición e invisibilización de su realidad según conveniencias políticas.

Por un lado, se subraya al sector Sur en la representación mediática, las narraciones negativas dominantes y el discurso político, para justificar el imaginario del caos moraly material (degeneración) como una realidad absoluta y sin solución, limitar inversiones públicas únicamente a tratamientos de sus problemáticas sociales, y motivar el apoyo ciudadano en proyectos de regeneración urbana, utilizando la vieja estrategia de la élite para materializar sus ideales de desarrollo mediante el encauce de los miedos y deseos de progreso de la población desde una metodología selectiva y excluyente. "El acoso permite ejercer un uso político del "caos" movilizando personas para apoyar proyectos específicos; empero, lo hace partir de un sentimiento y pensamiento de pánico moral y no de una reflexión profunda acerca de los retos de la ciudad” (Araya, 2010, p.198).

Por otro lado, se invisibiliza a los pobladores y territorios del Sur en propuestas que los tomen en cuenta como público meta de planes urbanos institucionales, inmobiliarios y de inversión, priorizando a los sectores demográficos que no habitan actualmente la capital, pero que se encuentran económica y socialmente más capacitados para ser parte del intencionado repoblamiento. "En este tipo de urbe, algunos de los intereses de turistas, intelectuales y artistas tienen cabida, mientras que los sectores populares están excluidos" (Araya, 2010, p.311) 
Para los sectores populares del casco central de San José, como los "Barrios del Sur" y algunos ubicados en la parte norte, las intervenciones se limitarán a la "cura moral" de sus problemáticas sociales, por ejemplo, a través del deseo de una "Cultura de Paz" para las comunidades "conflictivas"18; siendo esto una certificación oficial de las representaciones peyorativas generalizadas, pues por oposición inmediata, refiere a la dominancia de una realidad dificultosa, insegura y violenta que debe ser atendida por sobre cualquier otro tipo de intervención urbana material ${ }^{19}$; por lo que se continúa fortaleciendo y reproduciendo una imagen barrial antagónica, mientras que predominantemente se desprecia el valor de proyectos asociados a la infraestructura pública y el espacio urbano-barrial como alternativa viable para el fortalecimiento de valores, prácticas y actitudes positivas auto-gestionadas por sus habitantes.

\section{Conclusión}

Como se ha intentado evidenciar en los párrafos anteriores, las designaciones destructivas generalizadas hacia territorios y pobladores en la urbe (imaginario dominante), son producto de desconfianzas, prejuicios y antivalores que nos resistimos a asociar con nosotros mismos, condensándolos en espacios y pobladores particulares indistintamente de si la mayoría de estos corresponden de forma comprobable a las aseveraciones hechas o $\mathrm{no}^{20}$, o si acontecimientos similares puedan suceder en cualquier otro sector de la capital; de modo que siempre que haya un mal o una problemática percibida en la urbe, se vuelve sencillo encontrar responsables en territorios y personajes ya etiquetados con regularidad, y no en sistemas sociales, económicos, políticos y simbólicos inequitativos y excluyentes que le han fallado a sus pobladores en garantizarles una ciudad en la que todos puedan pertenecer.

Como toda aproximación a la temática de ciudad, y sobre todo en el enfoque de una problemática urbana compleja que no distingue disciplinas, nociones tecnócratas o tradicionales del urbanismo, ni líneas de pensamiento (se inclina más a la divergencia que a la convergencia de ideas), esta investigación deviene en un retrato general e

\footnotetext{
18 Iniciativa organizada desde Instituciones como el Programa Conjunto "Redes para la convivencia y comunidades sin Miedo", el Plan de Desarrollo Nacional 2010-2014, el Fondo para el Logro de los ODM, etc., en articulación con la Comisión Sembrando Paz en el Distrito Hospital, la Fuerza Pública, la Municipalidad de San José y asociaciones de desarrollo comunal.

19 Por ejemplo, desde los Ejes de Calidad de Vida del Plan de Desarrollo Urbano 2012-2016, el eje relacionado a la "Paz Ciudadana" está centrado en la inversión de dispositivos policiales, atención de armas, prevención de delitos, aumento de alarmas habitacionales y comerciales, etc. (Dependencias Municipales, 2012 p.71), lo cual demuestra no solo una distorsión del significado de armonía y paz como ausencia de conflictos y disentimientos sociales, sino que también evidencia una posición tergiversada de los símbolos de convivencia urbana pautados según mecanismos de control del pensamiento y comportamiento social, (cámaras, tapias, alambres, rejas, casetillas de seguridad, etc.), los cuales más bien perpetúan o denotan un ambiente de hostilidad y violencia simbólica para los ocupantes del espacio empírico. (referenciar con imágenes de territorio detalle barrio Cuba).

20 Simplificación de realidades socio-espaciales complejas e incomprendidas en la ciudad.
} 
incompleto sobre los modos con que se forma y transforma constantemente la ciudad a partir de la efervescencia de sus actores (sociedad civil, políticos, inversionistas y agentes inmobiliarios) y las herramientas que utilizan para hacer operativas sus intenciones en la misma (medios de comunicación, estrategias de urbanización y uso cotidiano), por lo que más que la respuesta a una interrogante inicial, está intencionada a ser la provocadora de nuevas preguntas, discusiones, investigaciones y acciones que reconozcan el principio creador del espacio urbano como una asociación inseparable entre sus composiciones y acontecimientos físico-formales (lo sensible), sus representaciones, memorias e identidades (lo inteligible), y los distintos códigos e instituciones sociales que lo albergan para volverlo tanto escenario de sus manifestaciones, como manifestación social por sí mismo (el entorno es lo que sus ocupantes hacen de él y como lo representan); esto es, como producto de un orden empírico, imaginario y social.

Entre las potenciales vertientes o seguimientos a la investigación, surge la posibilidad de aproximaciones interdisciplinarias enfocadas en contraponer las distintas representaciones que se generalizan para todo el territorio designado "Barrios del Sur", con problemáticas y realidades puntuales de cada barrio y ámbito barrial (problemas de violencia urbana, drogadicción y carencia de infraestructura) inscritos dentro de este denominativo, para determinar su relación, impacto y vías de acción en una escala más detallada; de manera que no se desestime la existencia de necesidades y demandas socio-espaciales reales que deben ser reconocidas y atendidas como tales, y no como una condición que representa a un sector de la ciudad y sus habitantes en su totalidad.

De igual manera, es importante un acercamiento a la representación de "Barrios del Sur” y su vínculo con la ocupación del espacio urbano, sin adoptar como consigna inicial al imaginario negativo (asumiendo esta etapa como realizada), de modo que se privilegien aquellas historias y características del entorno empírico que le den valor y sentido de apropiación desde sus ocupantes, por ejemplo: las noticias y narraciones de empoderamiento, las memorias recordadas con aprecio, el patrimonio histórico barrial, los proyectos e iniciativas que involucran la participación comunal e incluso autogestionadas por los habitantes del barrio, las características formales que enriquecen la experiencia socio-espacial, las manifestaciones cotidianas que transgreden las concepciones dominantes de uso (venta callejera, juegos en la acera), etc. Esto potenciaría nuevos descubrimientos, formas de interpretación y acercamientos a la temática de los "Barrios del Sur", los imaginarios urbanos y las posibilidades que su relación con el espacio vivencial aportarían a producciones territoriales, tanto a nivel discursivo, como formal. 
Con la intención de reforzar el entendimiento del espacio y su relación con el sentido y simbolismo individual y colectivo, se considera valioso continuar el presente tema de investigación con estudios desde campos de lo simbólico y el significado, como la Hermenéutica y la Semiótica del espacio urbano, en donde se vinculen los modos de pensamiento ciudadano y su facultad por elaborar patrones de comunicación y lenguaje verbal y formal, con los modos con que perciben, ocupan, interpretan, viven y organizan al territorio. Esto posibilitaría que los hallazgos del estudio entre lo que se imagina y se vive empíricamente en espacios urbanos como "Barrios del Sur", puedan ser llevados a criterios y lineamientos de diseño de manera eficiente y coherente con la realidad percibida.

Finalmente, si la presente problemática se asumió desde la construcción mediática del territorio según la imagen negativa dominante "Barrios del Sur", y su incidencia en el espacio urbano en donde se impone e instaura materialmente, entonces es importante considerar que la misma relación de influencia recíproca entre la dimensión social, empírica e imaginaria para la producción de la ciudad, establecida como premisa de estudio, sugiere posibilidades de investigación y propuestas académicas y aplicadas (prácticas participativas y trabajo de campo) para contrarrestar dicho fenómeno desde ejercicios que fomenten la experimentación, puesta en valor y acciones en el espacio urbano como medio de comunicación por sí mismo; es decir, aproximaciones que tengan como principio el estímulo de la convivencia socio-espacial en el barrio como herramienta territorial desde donde se potencia la articulación y construcción de los propios símbolos de representación, la opinión pública, imaginarios colectivos, órdenes políticos, identitarios (modos de ser, ver y ser visto), económicos, culturales, sociales, etc., y por lo tanto espacio empírico en potencia. 


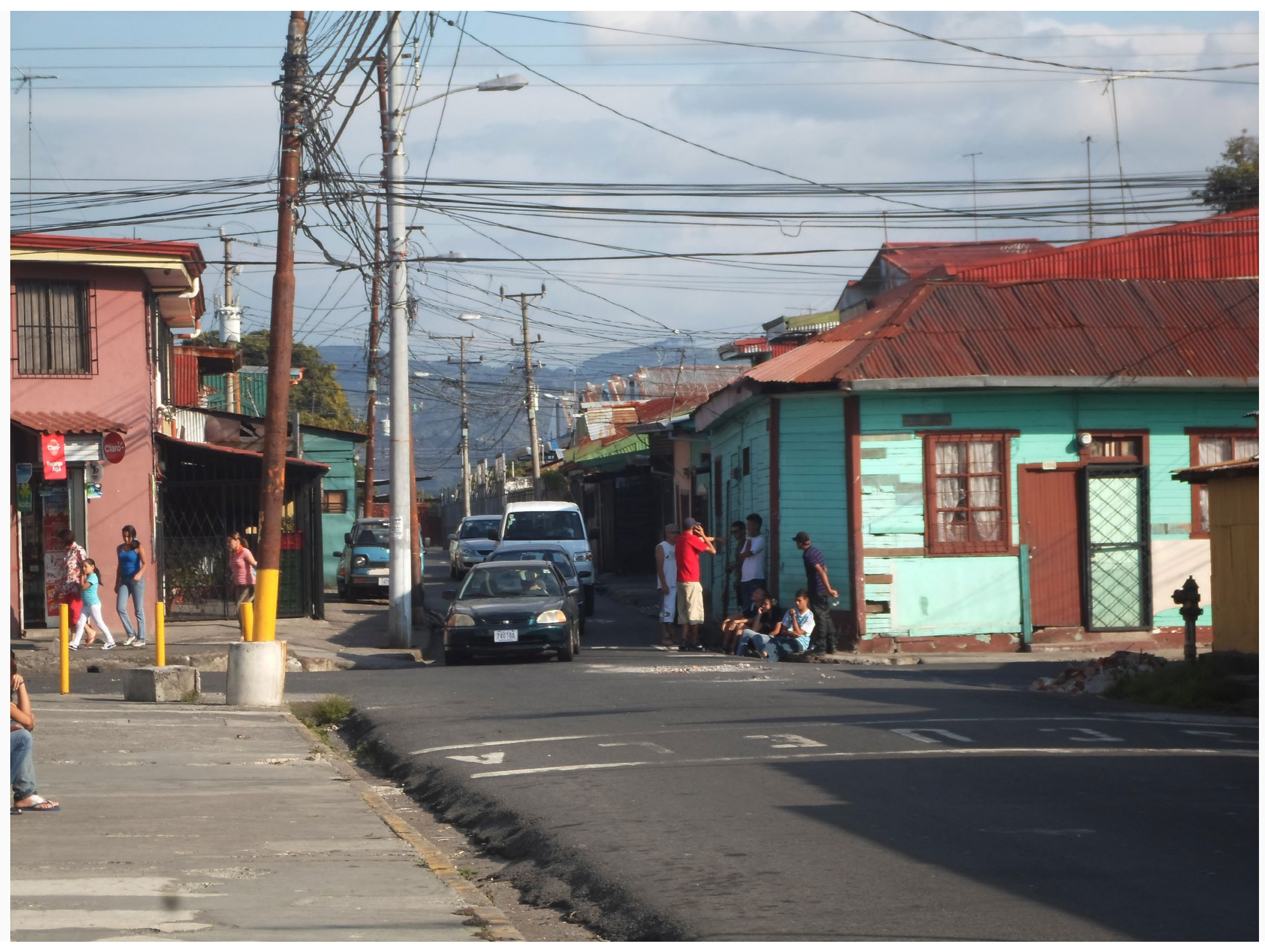

Figura 6. Visita de Campo a Barrio Cuba, Distrito Hospital, 2012; denota una realidad alterna a la descrita por el imaginario dominante, en donde se despliega un escenario barrial lleno de vida (actividades cotidianas, tertulia, flujos, etc). Eventos catalizadores y comunicadores de la producción del espacio urbano que deben ser potenciados para revertir las percepciones negativas "desde adentro" y "desde afuera". Imagen propia. 


\section{Referencias}

Araya, M.C. (2010). San José: de París en Miniatura al Malestar de la Ciudad. Medios de Comunicación e Imaginarios Urbanos. San José, Costa Rica: Editorial Universidad Estatal a Distancia.

Arguedas, C. (15 de febrero de 2004). Cuartuchos anidan miseria y delincuencia. La Nación. Recuperado de: http://wvw.nacion.com/ln_ee/2004/febrero/15/pais1.html Consejo Nacional de Política Económica y Social (Conpes), (2012). Política Nacional de Espacio Público (Documento 3718). Bogotá, Colombia: Departamento Nacional de Planeación.

Delgado, D. (18 de Octubre del 2012). Cinco personas irán a prisión por secuestro extorsivo contra hija de empresario. La Nación. Recuperado de: http://www.nacion. com/sucesos/personas-prision-secuestroextrorsivo-empresario_o_1299870009. html

Elkins, J. (2010). Un seminario sobre la teoría de la imagen. Estudios Visuales. Recuperado de: http://estudiosvisuales.net/revista/pdf/num7/o9_elkins.pdf

Instituto de Arquitectura Tropical (s.f.). San José Posible. Recuperado de: http://www. arquitecturatropical.org/EDITORIAL/documents/SAN\%20JOSE\%20POSIBLE.pdf

Lefebvre, H. (1974). La production de l'espace, Paris. Anthropos, 420.

Miranda, H. (2 de Junio del 2013). Joven muere tras balacera dentro de auto en Barrio Cuba. La Nación. Recuperado de: http://www.nacion.com/sucesos/Joven-balaceradentro-Barrio-Cuba_o_1345265469.html

Mora, E. (2013). Despoblamiento y Repoblamiento de San José Centro. Revista Ambientico, \#234, 6-48.

Municipalidad de San José (2011). Diagnóstico Cantonal. Recuperado de: https://www. msj.go.cr/informacion_ciudadana/SiteAssets/DIAGN\%C3\%93STICO\%20CANTONAL. pdf

Municipalidad de San José (2008). Plan de Desarrollo Municipal 2012-2016. Recuperado de: https://www.msj.go.cr/informacion_ciudadana/SiteAssets/Plan\%20 
Desarrollo\%20Municipal\%202012-2016\%20\%20vigente\%20mayo\%202013.pdf

Municipalidad deSanJosé(2008). Explicación del Plan deRegeneración y Repoblamiento de San José. Recuperado de: https://www.msj.go.cr/SiteAssets/conozca_su_ciudad/ expli_plan_regen_repob_sanjose.pdf

Oconitrillo, E. y Enríquez, F. (1997). "El Barrio Carit”. En: Historias de mi Barrio: El San José de ayer. (pp 231-243). San José, Costa Rica: Editorial San José.

Quesada, F. (2011). La modernizacion entre cafetales: San José, Costa Rica, 1880-1930. Editorial UCR, San José, Costa Rica.

Silva, A. (2006). Imaginarios Urbanos. Bogotá, Colombia. Editorial Tercer Mundo.

Ugarte, J. (2013). San José posible: un buen intento. RevistArquis, 2(1). Recuperado de: http://revistas.ucr.ac.cr/index.php/revistarquis/article/view/8712/8212

Vargas, O. (19 de marzo del 2004). Escolares agredieron a dos educadores. La Nación. Recuperado de: http://wvw.nacion.com/ln_ee/2004/marzo/19/pais11.html

Vargas, O. (12 de agosto de 2013). Escasean granos en bodegas de grupo que alimenta a niños e indigentes. La Nación. Recuperado de: http://www.nacion.com/nacional/ religion/indigentes-Asociacion_Obras_del_Espiritu_Santo_o_1359464303.html

Villalobos, R. (2014). Barrioscopio del Sur, Vías y Dispositivos de Imaginación desde el Espacio Urbano. Caso: Imaginario Dominante "Barrios del Sur" (Tesis de Licenciatura en Arquitectura). Universidad de Costa Rica. 

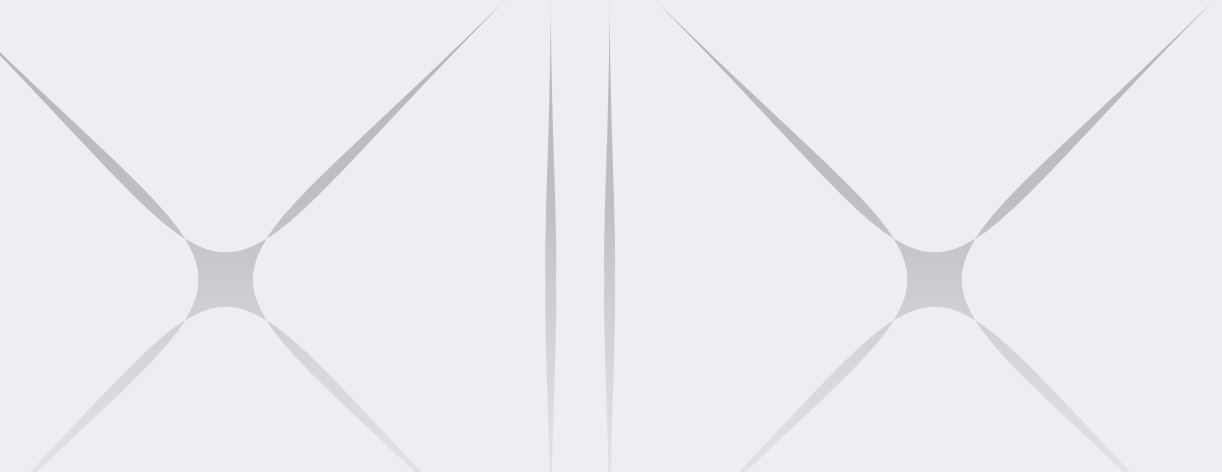

Este artículo forma parte de:

\section{REVISTARQUIS / 10}

Para más información, artículos, e instructivo de publicación, visite:

www.arquis.ucr.ac.cr/revistarquis.html 